\title{
Library Automation Systems Integration (Case: ELIB and SLiMS)
}

\author{
Meizano Ardhi Muhammad ${ }^{1}$, Mardiana $^{1}$
}

\begin{abstract}
The Library automation system help reduce much work need to be done by doing monotonous routine jobs with the help of technologies such as Barcode and RFID. Unila Library as the pioneer of RFID technology implementation in Lampung province face challenge in migration. Unila Library used SLiMS Library Automation System to manage collections, which use mainly barcode to identify collection. RFID uses allow collections to be scanned in gate and warn librarian. Unfortunately, SLiMS doesn't support SIP2 protocol which is needed by RFID devices (gate, kiosk) to function properly. Therefore, a solution must be made to address the migration of data and support SIP2 protocol. ELIB is a library automation software which support SIP2 protocol. So, library automation systems integration which synchronize both database in ELIB and SLiMS to keep up to date data and allow support for SIP2 protocol must be made in the form of middleware. Some of difficulties arise in integration was the development of both library automation systems which require fine tuning everytime update occurs and both systems in active use. Benchmarking is done to find anomaly and disreparancies of data. And, because the integration system is build as middleware, it remain flexible and open to future development. It can be concluded, Library automation systems integration require vigilance and keen observations into minuscule level especially because both systems are so different.
\end{abstract}

Keywords- library, RFID, ELIB, SLIMS, SIP2, middleware

\section{INTRODUCTION}

There's always a challenge to manage so many collections in library. Monotonous routine librarian jobs can be reduced with the help of technologies such as Barcode and RFID. Unila Library used SLiMS Library Automation System to manage collections, which use mainly barcode to identify collection. Barcode require the scanner to be in direct view of the barcode, which show limitation in securing the book from being taken by patron accidentally. RFID address this problem by allowing RFID tag to be scanned as long as it is in range (depend on the scanner spec, about $10-60 \mathrm{~cm}$ ). Using RFID allow collections to scanned using a gate and warn librarian. But, implementation RFID technology in Unila Library face challenge in migration. SLiMS doesn't support SIP2 protocol[1] needed by RFID devices (gate, kiosk) to function. Therefore, a solution must be made which address the migration of data and support SIP2 protocol. ELIB is a library automation software which support SIP2 protocol, therefore it can be use to take advantage of RFID technology devices. But, the database system and structure is different from SLiMS. SLiMS use MySQL and ELIB use MSSQL.And, SLiMS must remain active because the search catalogue module is required. So, library automation systems integration which synchronize both database in ELIB and SLiMS need to be made to keep up to date data and allow support for SIP2 protocol for RFID devices.

\section{THEORY}

\section{A. Library Automation System}

Library automation system in an integrated applications solution which help librarian do routine task. Two main activities in library are in circulation and cataloging. Both activities are supported in library integration system alongside with necessary feature in information system such as user management and authentication.

Automation of the library helps take some of the workload off of librarians and other staff members in the areas of acquisitions, cataloging and circulation, which in turn allows them to better serve their patrons. This extra time can lead to more programs being facilitated in the library and make library staff available to answer reference questions and help people who having trouble researching or finding the right information [2].

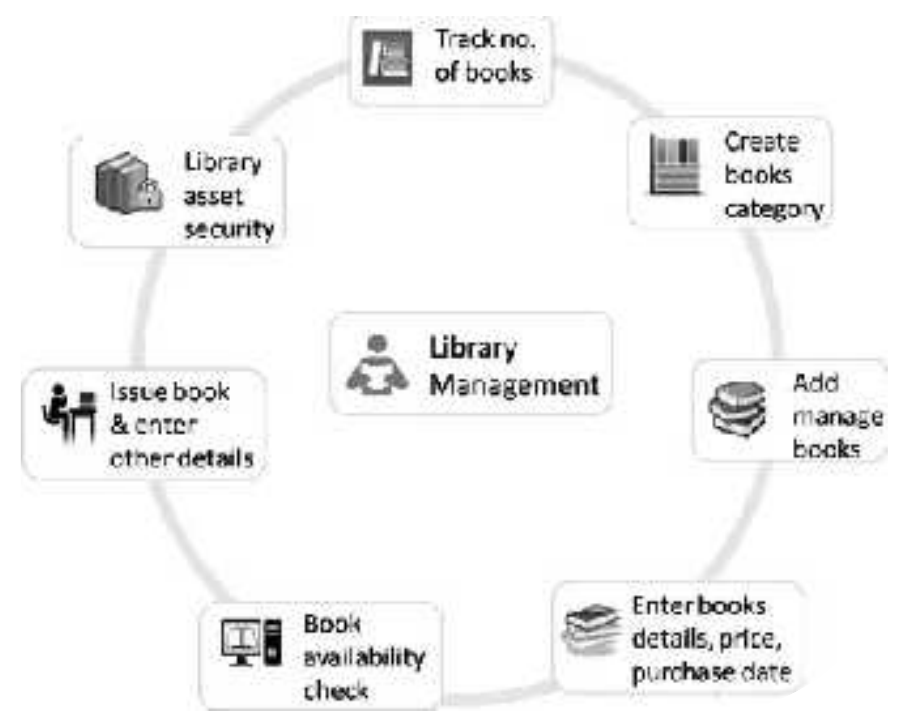

Fig 1. Library Automation and Management System [2]

Library automation can be defined as the use of computer and networking technologies in the library[3]. The areas of Library Automation include: Automation of library functions, Use of electronic resources within the library, Accessing remote electronic resources, Office automation, Patron services. And, with objectives: To improve the level of service and quality of output, to fulfill needs that cannot be achieved by manual system (Sharing of resources, information that appears only in electronic format).

\footnotetext{
${ }^{1}$ Department of Informatics, with Lampung University, Bandar Lampung, Indonesia (phone: +62-813-7935-2228; e-mail: meizano@ eng.unila.ac.id)
} 
This is supported by trends in library practice related to the needs to expand the online catalog, to intermix disparate systems, and to access networks[4]. Trends in library practice: Buy Standard Hardware, Buy Enough Capacity, Emphasize Networking Capabilities, Employ Flexible Software, Follow Standards, Use MARC Formats, Develop Local Expertise, Supervise the Database, Develop Close Relations with Campus Computer Services, and Plan for the Next System[5].

\section{A. SLiMS}

SLiMS is a library automation system build on top of open source technologies, mainly PHP and MySQL. The natures of SLiMS are free, multiplatform, web based, and open for contribution. SLiMS is free to modify and many organizations/library customized SLiMS according to their need, some even contributed back to the software repository. Indonesian library, which its main developer originated from, account for a huge percentage of user using SLiMS as the solution for library automation system. SLiMS supported SIP protocol version one. SLiMS provides many features such as bibliography database, circulation, membership management and many more that will help "automating" library tasks. SLiMS is licensed underGPL v3 [6].

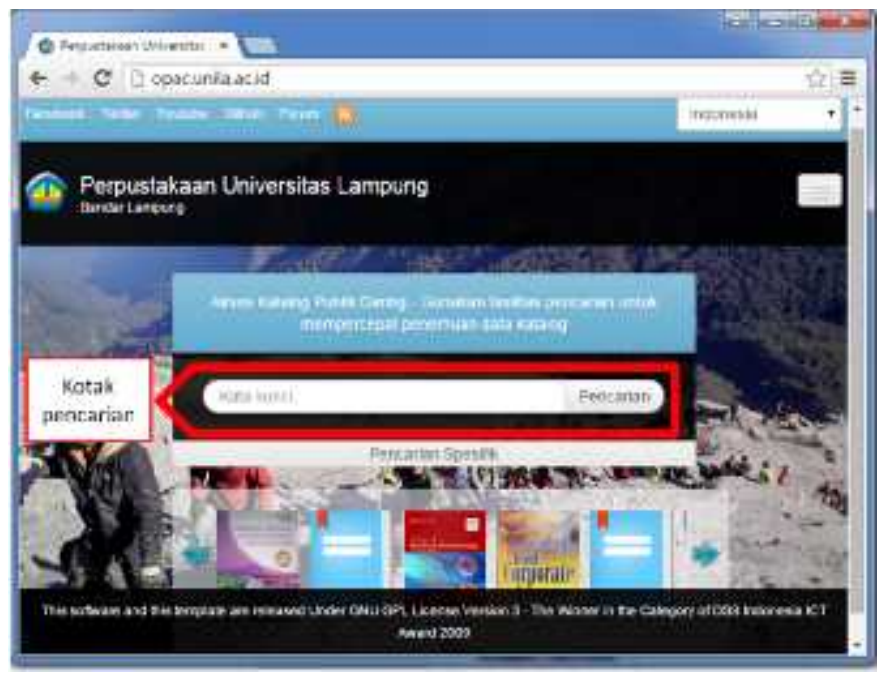

Fig 2. SLiMS search module

\section{B. $E L I B$}

ELIB is a library automation system to support Bibliotheca RFID library devices. The system support general activities in library automation system. By supporting RFID devices which connect from SIP2 protocol, ELIB can help to automate transaction through Self Service Kiosk, scanning collection, etc. One of the main draw of using ELIB is the developer is a subsidiary of Bibliotheca company which support SIP2 Protocol enabling the use of library automation devices.

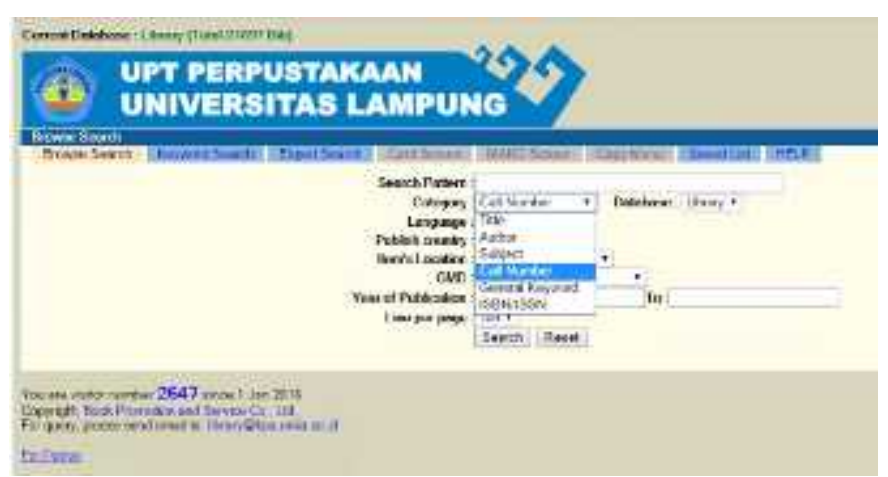

Fig 3. ELIB search module

\section{SIP2 Protocol}

SIP Protocol is a simple method of communicating between machine to machine using a formatted string which contains data. Version 2[1] add a security protocol to help reduce data breach. The protocol provides standard interface between library automation system and library automation devices. The protocol was developed by $3 \mathrm{M}$. SIP protocol enabling library to add new type of automated devices and services with minimal changes to the system. And, upgrade new version of automated devices with minimal or no change to the system.

\section{RFID in Library}

RFID is abbreviation for Radio Frequency Identification. RFID allow tagging of information. RFID, unlike barcode, doesn't require direct view of the tag. RFID scanner can detect RFID tag as long as it is within range. For example, RFID gate can scan RFID tag at $40-60 \mathrm{~cm}$ distance.

RFID is the latest technology to be used in library theft detection systems. Unlike EM (Electro-Mechanical) and RF (Radio Frequency) systems, which have been used in lib raries for decades, RFID-based systems move beyond security to become tracking systems that combine security with more efficient tracking of materials throughout the library, including easier and faster charge and discharge, inventorying, and materials handling[7].

A comprehensive RFID system has three components: (1) RFID tags that are electronically programmed with unique information; (2) readers or sensors to interrogate the tags; and (3) a server or docking station on which the software that interfaces with the automated library system is loaded. It is also possible to distribute the software among the readers and sensors.

While library RFID systems have a great deal in common with one another, including the use of high-frequency (13.56 $\mathrm{MHz}$, passive, read-write tags, there are some significant differences:

An RFID system may be a comprehensive system that addresses both the security and materials tracking needs of a library by replacing both EM strips and barcodes or it may be a part of a hybrid system that uses EM strips for security and RFID for materials tracking. All of the systems currently available are comprehensive RFID systems except for the hybrid system offered by $3 \mathrm{M}$. 
An RFID system may manage security by using a "theft" bit on the tag that can be turned on or off, or it may interface with an automated library system and query that system to determine the security status. Libramation and Tagsys use a "theft bit, Checkpoint uses an interface with an automated library system, Bibliotheca uses both, and $3 \mathrm{M}$ prefers to rely on EM technology for security.

The RFID system tags may contain only an identification number or they may contain considerable additional information, some of which may be permanent and some capable of being rewritten. The 74 bit tag used by Tagsys and the 95 bit tag used by Checkpoint can accommodate only identification, the 256 bit tag used by $3 \mathrm{M}$ can accommodate a small amount of additional information, and the 1024 bit used by Bibliotheca and Libramation can accommodate considerable additional information.

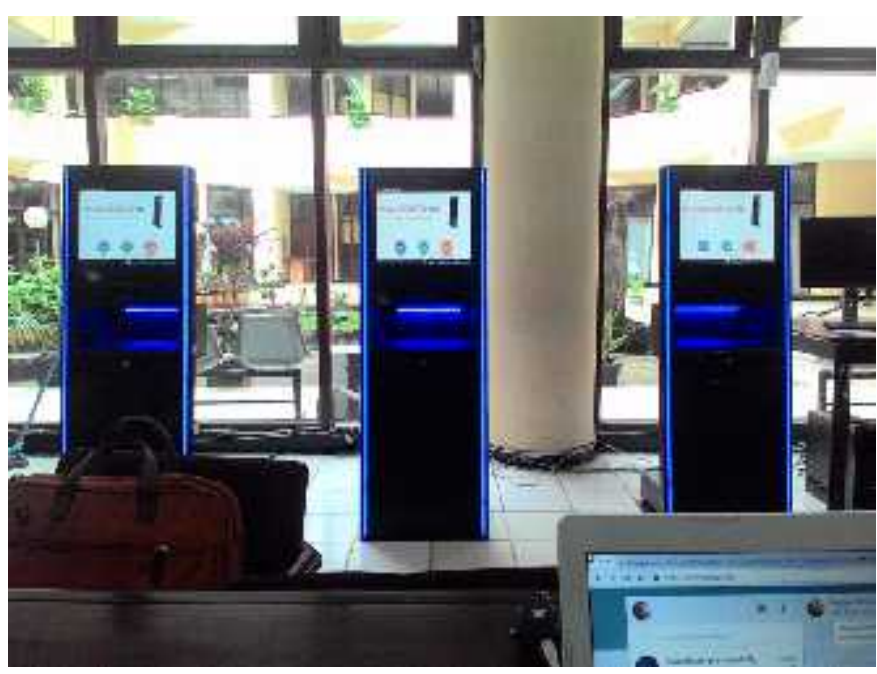

Fig 4. RFID Kiosk

\section{E. SymmetricDS}

SymmetricDS is open source software for both file and database synchronization with support for multi-master replication, filtered synchronization, and transformation across the network in a heterogeneous environment[8]. It supports multiple subscribers with one direction or bidirectional, asynchronous data replication. It uses web and database technologies to replicate data as a scheduled or near real-time operation. The software was designed to scale for a large number of nodes, work across low-bandwidth connections, and withstand periods of network outage. It works with most operating systems, file systems, and databases, including Oracle, MySQL, MariaDB, PostgreSQL, MS SQL Server (including Azure), IBM DB2, H2, HSQLDB, Derby, Firebird, Interbase, Informix, Greenplum, SQLite (including Android), Sybase ASE, and Sybase ASA (SQL Anywhere) databases.

\section{F. Pentaho}

Database synchronization between two different systems is a challenge because how syntax can be downright different. Pentaho help synchronization by addressing this need. One of its products, Pentaho Data Integration, prepares and blends data to create a complete picture of data relation and act upon it. The platform delivers accurate, analytics-ready data to end users from many sources. Pentaho visual tools eliminate coding and complexity. Pentaho manage big data and all data sources[9].

Pentaho Data Integration, with intuitive drag-and-drop data integration, can manage data agnostic connectivity spanning from flat files and RDBMS to Hadoop and beyond. Pentaho Data Integration features include:

- Graphical extract-transform-load (ETL) designer to simplify the creation of data pipelines

- $\quad$ Rich library of pre-built components to access, prepare, and blend data from relational sources, big data stores, enterprise applications, and more

- Powerful orchestration capabilities to coordinate and combine transformations, including notifications and alerts

Agile views for modeling and visualizing data on the fly during the data preparation process

Integrated enterprise scheduler for coordinating workflows and debugger for testing and tuning job execution

\section{Methodology}

Library Automation System Integrations require in depth analysis of pros and cons in implementing it. Spiral SDLC [10] address this need by doing risk analysis early before doing prototyping. And, because software continuous development, there will be more than one iteration to improve software. The iteration in spiral will control how much improvement to be done and how far should each iteration go.

\begin{tabular}{|l|l|}
\hline \multicolumn{2}{|c|}{ Analyzing Risk } \\
\hline Keep Using Slims & Using Elib \\
\hline Data Matching & \\
\hline \multicolumn{2}{|c|}{ Solution Design } \\
\hline Implementation \\
\hline
\end{tabular}

Fig. 5 RFID Kiosk

Risk is analyzed and based on pros and cons. Thus, Solution design, data matching and sync plan, is created to adhered to this plan. And, finally, implementation which consist of impelementation and testing (mainly for data inconsistensy). 
Table 1. Risk Analysis

\begin{tabular}{|c|c|c|}
\hline & SLiMS & ELIB \\
\hline Scenario & $\begin{array}{l}\text { Keep using } \\
\text { SLiMS }\end{array}$ & Migrating to ELIB \\
\hline Hazard & $\begin{array}{l}\text { SIP2 protocol } \\
\text { not available, } \\
\text { library devices } \\
\text { can not operate }\end{array}$ & $\begin{array}{l}\text { Failure to migrate } \\
\text { SLiMS Database }\end{array}$ \\
\hline Risk & Library devices & $\begin{array}{l}\text { Librarian, Library } \\
\text { Automation System }\end{array}$ \\
\hline $\begin{array}{l}\text { Existing } \\
\text { Control } \\
\text { Measure }\end{array}$ & none & Fallback to manual \\
\hline Evaluate & $\begin{array}{l}\text { Certain and } \\
\text { Major Severity }\end{array}$ & $\begin{array}{l}\text { Possible and Major } \\
\text { Severity }\end{array}$ \\
\hline $\begin{array}{l}\text { Implement } \\
\text { Control } \\
\text { Measure }\end{array}$ & $\begin{array}{l}\text { Developing } \\
\text { SIP2 Protocol }\end{array}$ & $\begin{array}{l}\text { Backup and } \\
\text { Synchronization } \\
\text { with SLiMS } \\
\text { database }\end{array}$ \\
\hline
\end{tabular}

Based on Table 1. Risk Analysis, Scenario Using ELIB is chosen. And, there were several things to be considered:

- Library must enable library RFID devices to serve member.

- Library devices require SIP2 protocol.

- Developing SIP2 protocol require expertise and experience in using SIP2 protocol. Which Unila library doesn't have the resources and time.

- $\quad$ SLiMS would need additional features to be able to fully utilize RFID technology.

- $\quad$ Migration of Data is more preferable because ELIB build with consideration of using RFID technology.

\section{LIBRARY AUTOMATION INTEGRATION DESIGN}

Although implementation in database can be quite different, Database of library automation systems in general contain the same data. Both database (SLiMS and ELIB) is analyzed to find which table and field contain the same data.

Data matching carry out to address which data match between the two database, SLiMS with MySQL and ELIB with MSSQL. Data Matching Map (Fig 4) show which group every important tables belong to. Additional table which only used for specific library software, either SLiMS or ELIB, is ignored.

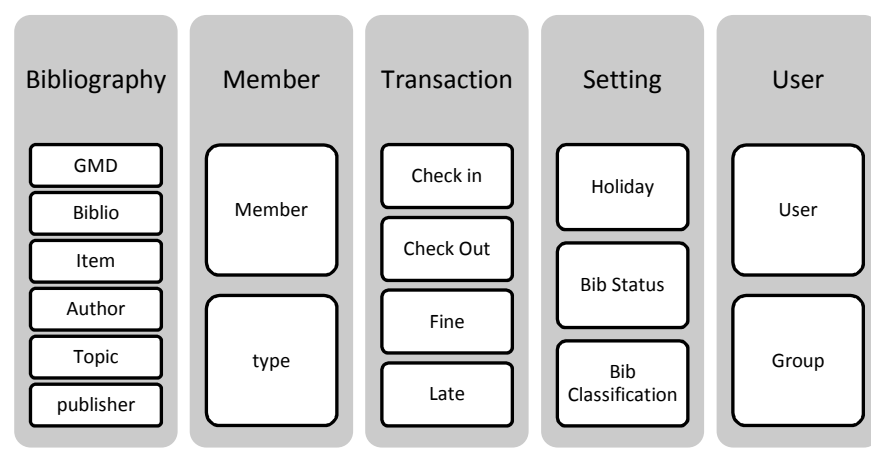

Fig 4. Data Matching Map

SLiMS have 10 bibliography tables, 2 member tables, 4 transaction tables, 4 setting tables, and 2 user tables. ELIB have 15 bibliography tables, 2 member tables, 4 transaction tables, 2 setting tables, and 3 user tables.

Tables from both database were analyze to map the matching field. Relation between table also mapped to show how every table related.

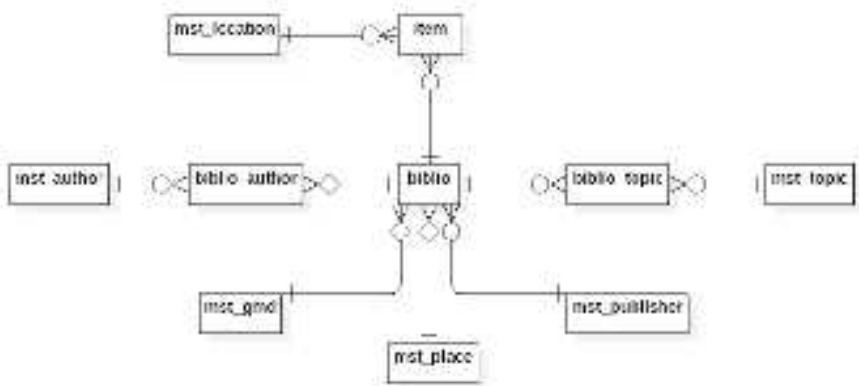

Fig 5. SLiMS Bibliography Tables relation

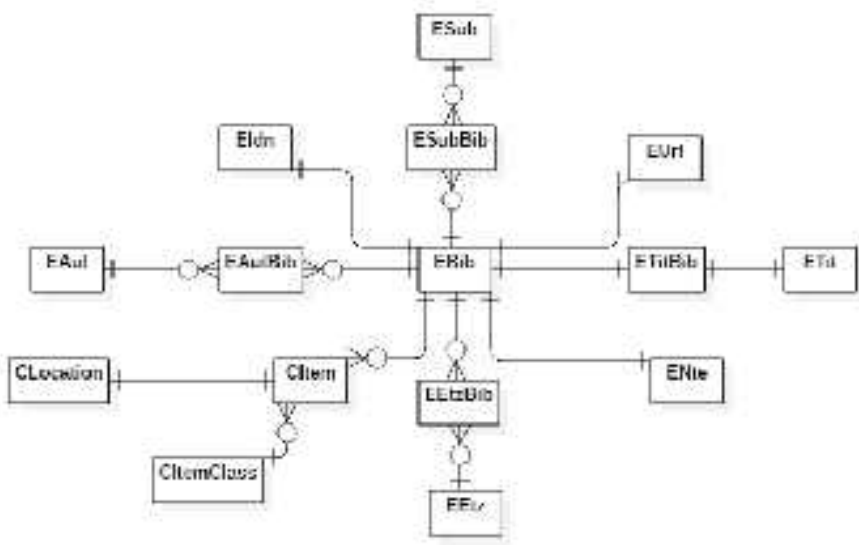

Fig 6. ELIB Bibliography Tables relation

From analysis, not all table and field need to find it's matching data. Only Bibliography need synchronizing. This is because SLiMS will not use all of its features, only the OPAC (Online Public Access Catalog) will be provided through SLiMS because of many patron familiarities with it. And, based on tables relation, a map of table matching is created.

Table 2. Bibliography Tables Matching

\begin{tabular}{lll}
\hline SLiMS & ELIB & Remark \\
\hline mst_gmd & CItemClass & $\begin{array}{l}\text { General Material } \\
\text { Designation }\end{array}$ \\
\hline \hline
\end{tabular}




\begin{tabular}{|c|c|c|}
\hline mst_author & EAut & Author \\
\hline biblio_author & EAutBib & $\begin{array}{l}\text { Joint between author and } \\
\text { biblio }\end{array}$ \\
\hline mst_publisher & EBib & Publisher \\
\hline mst_place & Ebib & Publisher place \\
\hline mst_topic & ESub & $\begin{array}{l}\text { Sub category/topic of } \\
\text { biblio }\end{array}$ \\
\hline biblio_topic & ESubBib & $\begin{array}{l}\text { Joint between biblio and } \\
\text { topic }\end{array}$ \\
\hline biblio & EBib & Bibliography \\
\hline- & $\begin{array}{l}\text { Eidn, Eurl, } \\
\text { ETIt, EtitBib, } \\
\text { ENte, Eetz, } \\
\text { EEtzBib }\end{array}$ & $\begin{array}{l}\text { Additional Bibliography } \\
\text { data which separate from } \\
\text { bibliography table }\end{array}$ \\
\hline item & CItem & Item/copy \\
\hline mst_location & CLocation & Item/copy location \\
\hline
\end{tabular}

\section{IMPLEMENTATION}

Different database design and technology between SLiMS (MySQL 5.5.27) and ELIB (MS SQL Server 2014) hindering exact synchronization of data. Therefore, it is unwise to keep both system able to update data. One must be the main data keeper. Because ELIB utilize the RFID technology, became the main database. SLiMS database, using synchronization tools, continuously sent data from ELIB everytime update occurs. Table mapping is implemented based on the design.

There were development hurdle in implementation which require a change of tools to enable data synchronization working as intended. Problem occur because SymmetricDS required to add trigger in ELIB database and it's proving quite problematic when update occur in ELIB Thus, Pentaho Data Integration came in as a replacement, which didn't require trigger in the main database, and become the one that is used for impementation.

After implementation and testing carry out, testing show working features of Unila Library Automation System for both SLiMS and ELIB.

Table 3. Library Automation Systems Working Features

\begin{tabular}{lll}
\hline Feature Category & SLiMS & ELIB \\
\hline Bibliography & OPAC & OPAC, Cataloging \\
Member & View only & All \\
Transactions & N/A & Circulation \\
Setting & N/A & All \\
User & N/A & All \\
SIP2 Protocol & N/A & Library Devices \\
\hline \hline
\end{tabular}

\section{CONCLUSION}

After several iterations of development and bugfix, both automation library systems seems to run normally and able to work as intended. And, because the integration system is build as middleware, it remain flexible and open to future development. Risk analysis reduce the work need to be done by addressing risk and choosing scenario, which in this case is data migration to ELIB. Although, at fundamental level, data in library is similiar, in implementation can be quite vastly different. Different database technologies require tools to synchronize, and this cause two experiment to find which tools best for synchronize database between SLiMS and ELIB. Unila library able to utilize SIP2 protocol and enable the use of library devices such as Self Service Kiosk. It can be concluded, Library automation systems integration require vigilance and keen observations into minuscule level especially because both systems are so different.

\section{REFERENCES}

[1] 3M, 3M Standard Interchange Protocol Version 2.00.: 3M, 2006.

[2] LIBRARY MANAGEMENT SOFTWARE. (2016, August) Advantages of Library Automation. [Online]. http://www.librarysoftware.in/adv-libraryautomation.html

[3] K.T. Lam. (2002, May) Issues in Library Automation. [Online]. http://ihome.ust.hk/ lblkt/diploma/libauto/libauto.html

[4] Diane R. Tebbetts, "EXPANDABILITY, FLEXIBILITY, COMPATIBI-LITY: KEY MANAGEMENT CONSIDERATIONS IN ACADEMIC LIBRARY AUTOMATION," in The 12th International Conference on New InformationTechnology, Beijing, 2001.

[5] Geo-Data Systems Limited. (2016, August) Digital Library Management System (DLMS). [Online]. http://www.geo-datasystems.com/library-managementsystem/

[6] Senayan. (2016, July) SLiMS. [Online]. http://SLiMS.web.id/web/

[7] Richard W. Boss. (2004, May) RFID Technology for Libraries. [Online]. http://www.ala.org/PrinterTemplate.cfm?Section=techn otes\&Template=/ContentManagement/HTMLDisplay.cf $\mathrm{m} \&$ ContentID $=68138$

[8] JumpMind. (2016, July) SymmetricDS | Open Source Database Replication. [Online]. https://www.symmetricds.org/

[9] Pentaho. (2016, August) Pentaho Data Integration. [Online]. http://www.pentaho.com/product/dataintegration

[10] Roger S. Pressman and Bruce R. Maxim, Software Engineering: a Practitioner's Approach, 8th ed. United States of America: McGraw-Hill Education, 2015. 